\title{
Improvement of Alumina Dissolution from the Mechanically Activated Dross Using Ultrasound-Assisted Leaching
}

\author{
Thi Thuy Nhi Nguyen and Man Seung Lee* \\ Department of Advanced Materials Science \& Engineering, Institute of Rare Metal, \\ Mokpo National University, Chonnam 58554, Republic of Korea
}

\begin{abstract}
Aluminum dross results from the re-melting of used aluminum cans, and is a valuable resource containing alumina. In general, aluminum dross contains oxides of $\mathrm{Al}, \mathrm{Ca}, \mathrm{Fe}, \mathrm{Mg}$, $\mathrm{Si}$ and $\mathrm{Ti}$ and some salts. As a continuation of the previous work to recover pure alumina from the dross, the effect of employing ultrasound wave in the $\mathrm{NaOH}$ solution was investigated to improve the leaching percentage of alumina from the mechanically activated dross. The use of ultrasound improved the leaching percentage of alumina from $35 \%$ to $60 \%$ and resulted in a leaching solution where the purity of aluminate ion was $99 \%$. Among the optimum conditions (5 M NaOH, $50{ }^{\circ} \mathrm{C}, 4 \mathrm{~h}$, pulp density of $100 \mathrm{~g} / \mathrm{L}$ and ultrasonic power $100 \mathrm{~W}$ ), leaching time had a remarkable effect on the dissolution of alumina in the presence of ultrasound. The combined effect of ultrasound and the addition of $\mathrm{CaCl}_{2}$ and organic acids to the $\mathrm{NaOH}$ solution was also investigated. Roasting of the black dross with $\mathrm{CaCl}_{2}$ followed by ultrasound leaching did not improve the leaching percentage of alumina. The presence of organic acids in the $\mathrm{NaOH}$ solution increased the leaching percentage of alumina as well as silica, and thus was not favorable for recovering pure aluminate solution from the black dross.
\end{abstract}

(Received December 4, 2018; Accepted January 18, 2019)

Keywords: black dross, ball milling, $\mathrm{NaOH}$ leaching, alumina, ultrasound wave

\section{INTRODUCTION}

Aluminum dross is produced by the treatment of secondary resources containing $\mathrm{Al}$ metal. This dross consists of a mixture of free $\mathrm{Al}$ metal and nonmetallic substances such as aluminum oxide, nitride, carbide, salts, metal oxides, and other elements [1]. The small amount of $\mathrm{Al}$ metal present in dross is recovered from the dross, and the residue after this treatment is called black dross. However, some Al metal and several metal oxides are still present in black dross. Therefore, the recovery of valuable components in black dross is important and necessary.

In the hydrometallurgical process, alumina and other oxides are dissolved from the black dross by employing either acid or alkaline solutions [2-4]. Alkaline leaching offers the selective leaching of alumina over other oxides

- Thi Thuy Nhi Nguyen : 박사과정, 이만승 : 교수

*Corresponding Author: Man Seung Lee

[Tel: +82-61-450-2492, E-mail: mslee@mokpo.ac.kr]

Copyright (c) The Korean Institute of Metals and Materials from black dross, but the leaching percentage of alumina is generally low $[4,5]$. In order to improve the leaching percentage of alumina without affecting the purity in the leaching solution, the choice of chemicals and the selection of effective methods are key to developing a new process.

In recent years, the use of ultrasound has become more common in metallurgy as an auxiliary means during the ore leaching process. Ultrasound consists of a series of longitudinal waves with differences in density that spread through the medium [7]. Irradiating ultrasonic energy in solution causes bubble formation and subsequent violent collapse, in a process known as "acoustic cavitation" [8]. This may cause direct erosion on the surface of the particle, and the de-aggregation of particles, which can hinder agglomeration [9]. The use of ultrasonic energy has a number of benefits, including optical, electrical, mechanical, thermal, chemical and biological effects [10,11].

Many researchers have employed ultrasound in the heavy metal leaching process to increase the extraction of metals $[12,13]$. The application of ultrasonic energy in hydrometallurgy 
has primarily concentrated on the treatment of heavy metals and precious metals, but little research has been performed on alumina production. In particular, no work has been reported on the selective dissolution of alumina from black dross employing ultrasound.

Since alumina is amphoteric, alumina can be dissolved in either acidic or alkaline solutions. In general, the leaching percentages of alumina and silica from black dross in $\mathrm{NaOH}$ solution are $80 \%$ and $68 \%$, respectively [14]. This makes it necessary to remove a large amount of dissolved silica from the leaching solution to obtain a pure $\mathrm{Al}(\mathrm{III})$ solution. Mechanical activation of black dross by ball milling followed by $\mathrm{NaOH}$ leaching leads to a leaching solution of $\mathrm{Al}(\mathrm{III})$ with $98 \%$ purity [15]. However, the leaching percentage of alumina was around 35\% [15], and thus further work is needed to improve the leaching of alumina from the mechanically activated dross.

The use of auxiliary energies is one way of increasing the leaching efficiency, by boosting transport phenomena. Ultrasound has proven to be a very effective tool for enhancing reaction rates by inducing a number of chemical and mechanical effects in the reaction medium [16]. It can improve the traditional leaching process and become a costefficient method for heavy metal recovery.

In this study, the effect of ultrasound on the alkaline leaching of alumina from mechanically activated black dross was investigated by varying leaching temperature and time and stirring speed. The combined effect of ultrasound, and the addition of different chemicals $\left(\mathrm{CaCl}_{2}\right.$ and organic acids) to the $\mathrm{NaOH}$ solution, on the leaching of alumina and silica was also investigated.

\section{EXPERIMENTAL}

\subsection{Materials}

The salts present in black dross were dissolved in water at $90{ }^{\circ} \mathrm{C}$ [14]. After drying the residues in an oven, the dried residues with an average particle size $<150 \mu \mathrm{m}$ were employed in the leaching experiments. A vertical planetary ball mill (Fritsch Pulverisette 7 Bead Mill, Fritsch, Idar-Oberstein, Germany) with a rotation speed up to $800 \mathrm{rpm}$ was employed in the mechanical activation of the black dross. Mechanically activated samples were prepared as follows:
Table 1. The chemical composition of black dross after water leaching. (unit: $w t \%$ )

\begin{tabular}{ccccccc}
\hline Element & $\mathrm{Al}$ & $\mathrm{Ca}$ & $\mathrm{Fe}$ & $\mathrm{Mg}$ & $\mathrm{Si}$ & $\mathrm{Ti}$ \\
\hline $\begin{array}{c}\text { Residue after } \\
\text { water leaching }\end{array}$ & 40.52 & 3.55 & 8.34 & 2.86 & 15.13 & 12.01 \\
\hline
\end{tabular}

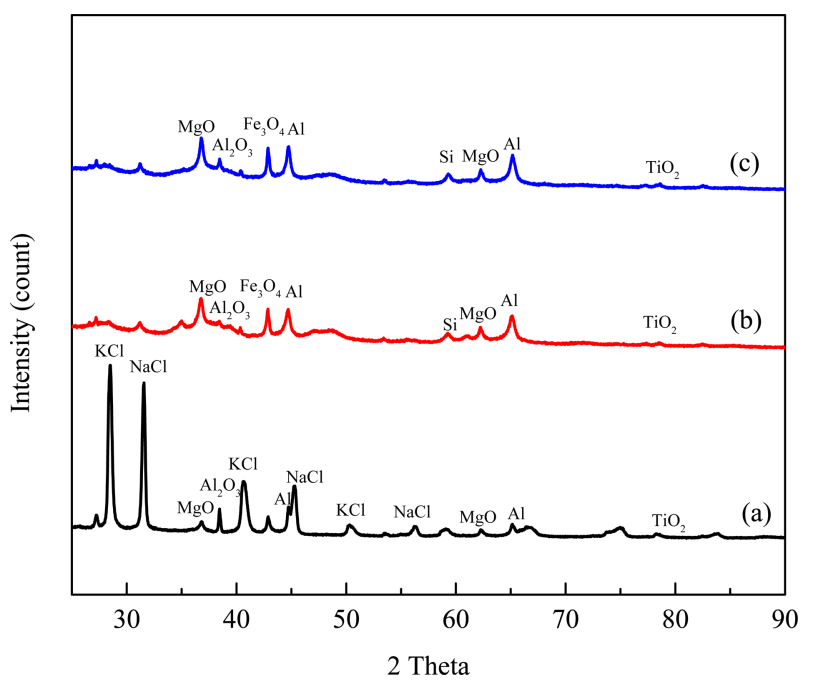

Fig. 1. XRD patterns of black dross before and after treatment. (a) raw black dross; (b) pretreated black dross with water (c) mechanically activated black dross.

the black dross after water leaching ( $8 \mathrm{~g}$ ) was added into a vessel with $40 \mathrm{~g}$ agate balls (a ball was $6 \mathrm{~mm}$ in diameter) with the weight ratio of ball/black dross of $5: 1$ and then milled for $1 \mathrm{~h}$ at $400 \mathrm{rpm}$. The mixture of mechanically activated dross and $\mathrm{CaCl}_{2}$ was prepared by varying the weight ratio of $\mathrm{CaCl}_{2}$ and black dross (mass of $\mathrm{CaCl}_{2} /$ mass of black dross) as $0.5,1,1.5,2,2.5$. The mixture was transferred to a corundum crucible and heated in an SX-GD7123 muffle furnace. The temperature protocol was 30 to $500{ }^{\circ} \mathrm{C}$ with a heating rate of $10^{\circ} \mathrm{C} / \mathrm{min}$, followed by continuous heating under $500{ }^{\circ} \mathrm{C}$ for 2 hours. The mechanically activated dross was used in these experiments. The heat treated mixtures were then allowed to naturally cool to room temperature.

The chemical composition of the black dross after water leaching was determined using X-ray fluorescence spectrophotometry (XRF, Hitachi, Tokyo, Japan). Point analyses were taken with the XRF operated at $15 \mathrm{kV}$. Table 1 shows the chemical composition of the black dross after water leaching. The structure of the raw black dross, the residues after water leaching and the ball-mill-treated black 
dross were characterized by X-ray diffraction (XRD) (D8 Advance (Bruker AXS, Karlsruhe, Germany)) with $\mathrm{Cu} \mathrm{Ka}$ (40 kV/40 mA, $\gamma=0.15406 \mathrm{~nm}$ ) radiation (Fig. 1).

Figure 1 shows that the as-received black dross contained significant amounts of $\mathrm{KCl}$ and $\mathrm{NaCl}$ (see Fig. 1a) which disappeared after water leaching (see Fig. 1b). Twice leaching with water at $90{ }^{\circ} \mathrm{C}$ led to the complete removal of $\mathrm{NaCl}$ and $\mathrm{KCl}$ from the black dross. The leaching solution was prepared by dissolving extra pure sodium hydroxide (Duksan Co.) in doubly distilled water.

\section{2. $\mathrm{NaOH}$ leaching}

The leaching experiments with the mechanically activated dross were carried out in a $500 \mathrm{~mL}$ three-neck round bottom flask (Duran Triple Neck Flask, Germany) which was submerged in an ultrasonic bath (WUC-A02H, 40kHz, Ultrasonic Cleaner, $40 \mathrm{kHz}, 1.8$ Lit., USA). The frequency of the ultrasonic waves was $40 \mathrm{kHz}$ and power was kept at a maximum of $100 \mathrm{~W}$. Teflon tape was used to seal the outside joints of the glassware to avoid evaporation loss. The slurry was stirred at $200 \mathrm{rpm}$ and at the temperature of $50{ }^{\circ} \mathrm{C}$ except for experiments on the effect of stirring speed and temperature.

At desired time intervals slurry samples were taken and filtered using vacuum filtration. The filtered residues were washed several times with distilled water until the filtrate became completely clean and then dried at $60^{\circ} \mathrm{C}$ for $48 \mathrm{~h}$. The morphologies of the leaching residue of the mechanically activated dross was investigated by Field Emission scanning electron microscopy (FE-SEM) (S4800, Hitachi, Tokyo, Japan). The weight percentage of alumina in the residue after $\mathrm{NaOH}$ leaching, and the concentration of minor elements in the solution, was measured by XRF, and inductively coupled plasma optical emission spectrometers ICP-OES (Spectro Arcos), respectively. The leaching percentage of alumina was calculated using Eq. (1), while that of the minor elements was calculated with Eq. (2).

Leaching percentage of alumina $=$

$$
\frac{W_{A l(\text { initial })}-W_{A l(\text { residue })}}{W_{A l(\text { initial })}} \times 100 \%
$$

Leaching percentage of minor components $=$

$$
\frac{C_{A} \times V}{W_{A(\text { initial })}} \times 100 \%
$$

where $\mathrm{W}_{\mathrm{Al}(\text { initial) }}$ and $\mathrm{W}_{\mathrm{Al}(\text { residue) }}$ represent the weight of alumina in the samples before and after the leaching experiments. $\mathrm{C}_{\mathrm{A}}$ and $\mathrm{V}$ refer to the concentration of minor elements in the leaching solution and the volume of leaching solution after filtration, respectively.

\section{RESULTS AND DISCUSSION}

The optimum conditions for the selective dissolution of alumina from the mechanically activated dross were obtained from a previous work: $5 \mathrm{M} \mathrm{NaOH}, 50^{\circ} \mathrm{C}, 2 \mathrm{~h}$, pulp density of $100 \mathrm{~g} / \mathrm{L}$ [15]. At this leaching condition, the purity of $\mathrm{Al}(\mathrm{III})$ in the leaching solution was higher than $98 \%$ but the leaching percentage of alumina was only around 35\% [15]. $\mathrm{No} \mathrm{Ca}, \mathrm{Fe}, \mathrm{Mg}$ and $\mathrm{Ti}$ oxides were dissolved, except for alumina and silica, at every $\mathrm{NaOH}$ concentration studied.

Therefore, to find the optimum conditions to improve the leaching of alumina from the mechanically activated dross, the effect of ultrasound was investigated. The dross which had been mechanically activated at $400 \mathrm{rpm}$ for $1 \mathrm{~h}$ was employed for all experiments in this work.

\subsection{Effect of temperature}

In order to investigate the effect of temperature on the dissolution of metal oxides in the presence of ultrasound, the mechanically activated dross was leached at varying temperatures from 30 to $100{ }^{\circ} \mathrm{C}$ for $2 \mathrm{~h}$. In these experiments, the concentration of $\mathrm{NaOH}$ and pulp density were the same as the optimum conditions obtained from the previous work: $5 \mathrm{M} \mathrm{NaOH}$ and the pulp density of $100 \mathrm{~g} / \mathrm{L}$ [15]. In these experiments, the ultrasound power was fixed at $100 \mathrm{~W}$.

The effect of temperature on the leaching of the oxides with ultrasound of $100 \mathrm{~W}$ is illustrated in Fig. 2. The leaching percentage of alumina slightly increased from 38 to $44 \%$ as the temperature increased from 30 to $50{ }^{\circ} \mathrm{C}$, and then was constant, irrespective of the temperature. When applying ultrasound to an alkaline leaching process, ultrasonic waves create liquid cavitation that can blow up the surface of the solid. This generates highly reactive surfaces causing transient high temperature and pressure at 


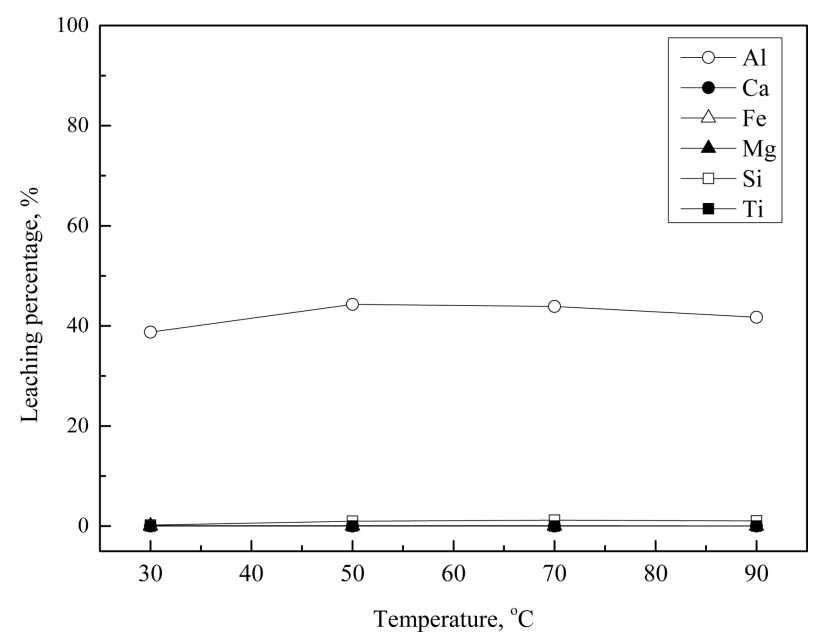

Fig. 2. Effect of reaction temperature on the ultrasound-assisted leaching of the oxides from the mechanically activated dross in $5 \mathrm{M}$ $\mathrm{NaOH}$ solution. (reaction time: $2 \mathrm{~h}$, stirring speed: $200 \mathrm{rpm}$, pulp density: $100 \mathrm{~g} / \mathrm{L}$, ultrasonic power $100 \mathrm{~W}$ ).
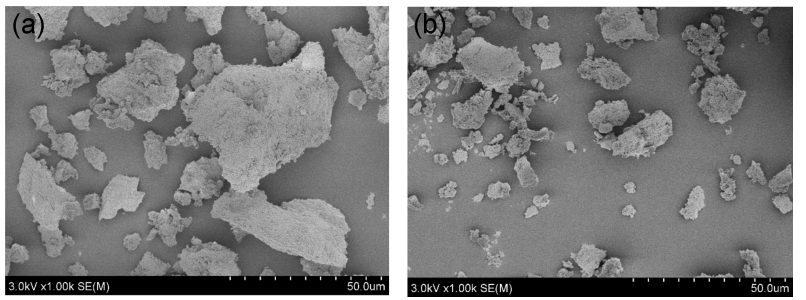

Fig. 3. SEM images of mechanically activated black dross after alkaline leaching: (a) without ultrasonic wave; (b) with ultrasonic wave. (reaction time: $2 \mathrm{~h}$, reaction temperature: $50{ }^{\circ} \mathrm{C}$ stirring speed: $200 \mathrm{rpm}$, pulp density: $100 \mathrm{~g} / \mathrm{L}$, ultrasonic power $100 \mathrm{~W}$ ).

the surface, which produces the formation of surface defects and deformations, and thus increases the surface area of friable solid [17-19]. Accordingly, the impact of ultrasound may accelerate the leaching of components which have higher solubility, and thus result in an increase in leaching efficiency for the metal. At the same time, ultrasonic waves may also enhance the settling of metal colloid particles with lower solubility and thus reduce their leaching efficiency [20].

The SEM images reveal the differences in the microstructure of the leaching residues of the mechanically activated dross in the presence and absence of ultrasonic treatment under the optimum conditions. Comparing Fig. (3a) and (3b), the particle size produced by ultrasonic treatment was finer than that produced by regular treatment. These particles became smaller and looser with the ultrasonic leaching. These phenomena confirm that the ultrasonic energy can shatter solid particles and hinder the growth of solid grains, which is beneficial for the solidliquid reaction, and thus promotes the leaching of the components [10].

\subsection{Effect of leaching time}

In order to investigate the effect of leaching time, experiments were conducted with varying times from $2 \mathrm{~h}$ to $10 \mathrm{~h}$. The mechanically activated dross was leached using $5 \mathrm{M} \mathrm{NaOH}$ solution at a pulp density of $100 \mathrm{~g} / \mathrm{L}$ at $50^{\circ} \mathrm{C}$. Within our experimental range, the leaching percentage of alumina was about $60 \%$, while that of other oxides was nearly zero at any leaching time (see Fig. 4).

The cavitation effect of ultrasound was significant within the leaching time up to $4 \mathrm{~h}$. When leaching time was longer than $4 \mathrm{~h}$, there was little change in the leaching percentage of alumina. Unlike alumina, the leaching percentage of silica was very low and became reduced as leaching time increased. This might be attributed to the precipitation of sodalite which occurred between aluminate and silicate ions in the leaching solution [21]. In other words, dissolved silicate ions can form a precipitate with aluminate ions during the leaching reaction.

Eqs. (3) and (4) represent the leaching of alumina and the precipitation reaction of sodalite in our experiments.

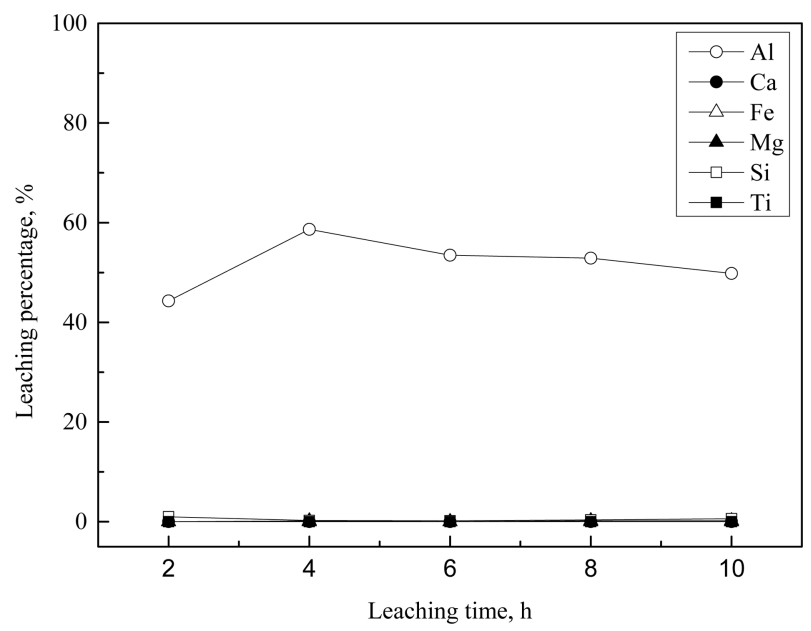

Fig. 4. Effect of leaching time on the leaching of the oxide from mechanically activated black dross by ultrasound-assisted leaching in $5 \mathrm{M} \mathrm{NaOH}$ solution at $50^{\circ} \mathrm{C}$. (pulp density: $100 \mathrm{~g} / \mathrm{L}$, stirring speed: $200 \mathrm{rpm}$, ultrasonic power $100 \mathrm{~W}$ ). 

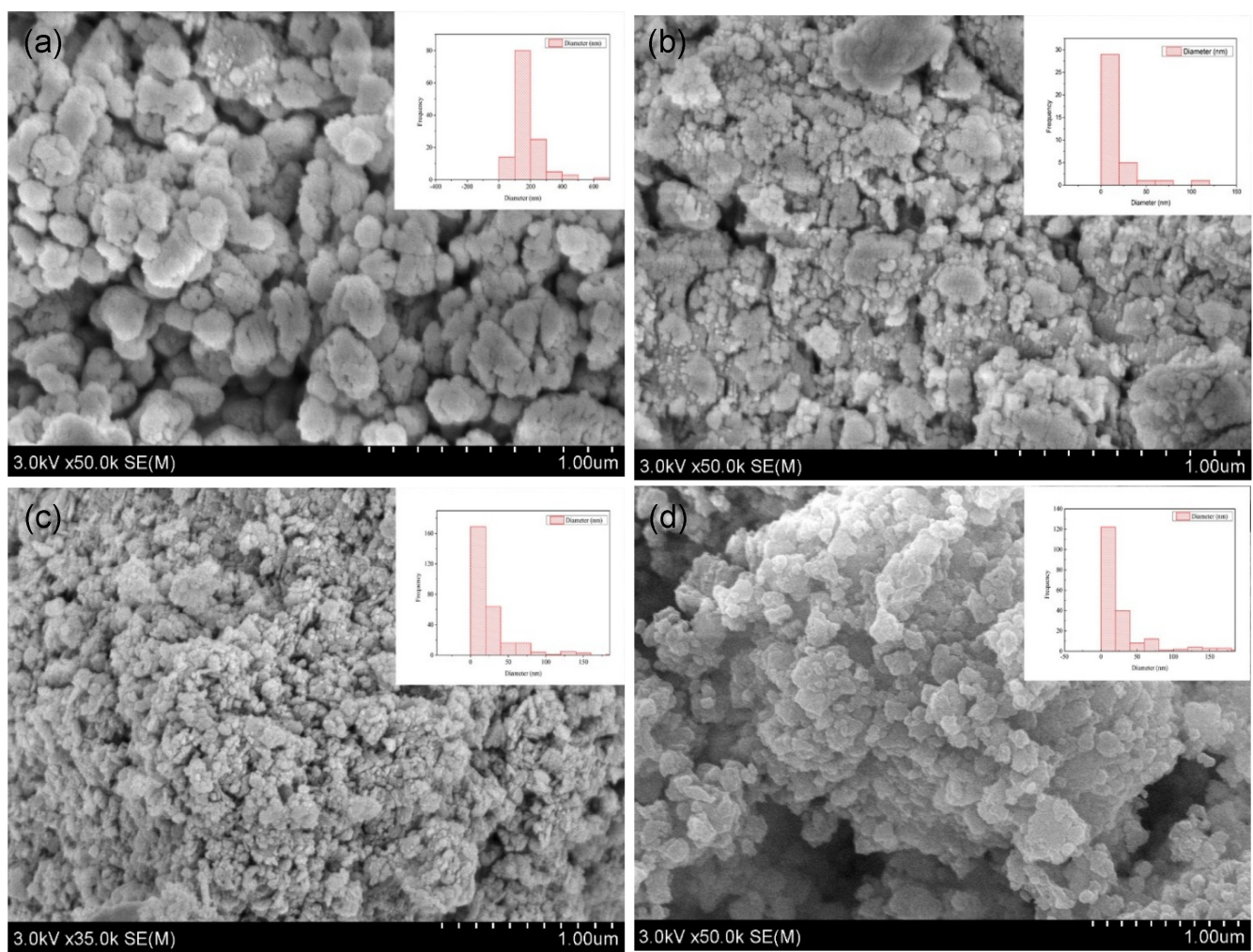

Fig. 5. SEM images of mechanically activated black dross after alkaline leaching: (a) without ultrasonic wave (reaction time: 2 h); (b) (c) (d) with ultrasonic wave. (reaction time: $2 \mathrm{~h}, 4 \mathrm{~h}, 6 \mathrm{~h}$ ).

$$
\begin{aligned}
& \mathrm{OH}^{-}+\mathrm{Al}_{2} \mathrm{O}_{3}+\mathrm{H}_{2} \mathrm{O}=\mathrm{Al}(\mathrm{OH})^{-} \\
& 6 \mathrm{H}_{2} \mathrm{SiO}_{4}^{2^{-}}+6 \mathrm{Al}(\mathrm{OH})_{4}^{-}+6 \mathrm{Na}^{+} \\
& \mathrm{Na}_{6}\left[\mathrm{AlSiO}_{4}\right]_{6} \cdot 4 \mathrm{H}_{2} \mathrm{O}+12 \mathrm{OH}+8 \mathrm{H}_{2} \mathrm{O}
\end{aligned}
$$

Similar observations were obtained by SEM in Fig. 5. The mechanically activated black dross after alkaline leaching without ultrasonic wave contained angular particles with different sizes but was broken into much smaller particles after treatment by ultrasonic waves. Large clusters with a typical size of several micrometers were observed, due to the aggregation of smaller nanoparticles [22].

\subsection{Effect of stirring speed}

Stirring of the leaching systems facilitates the intimate mixing of black dross and reagents as well as mass transfer. In the absence of stirring, the turbulence caused by ultrasound is not enough to make the leaching reaction proceed [23]. Therefore, the effect of stirring speed in the presence of ultrasound was investigated in this work.

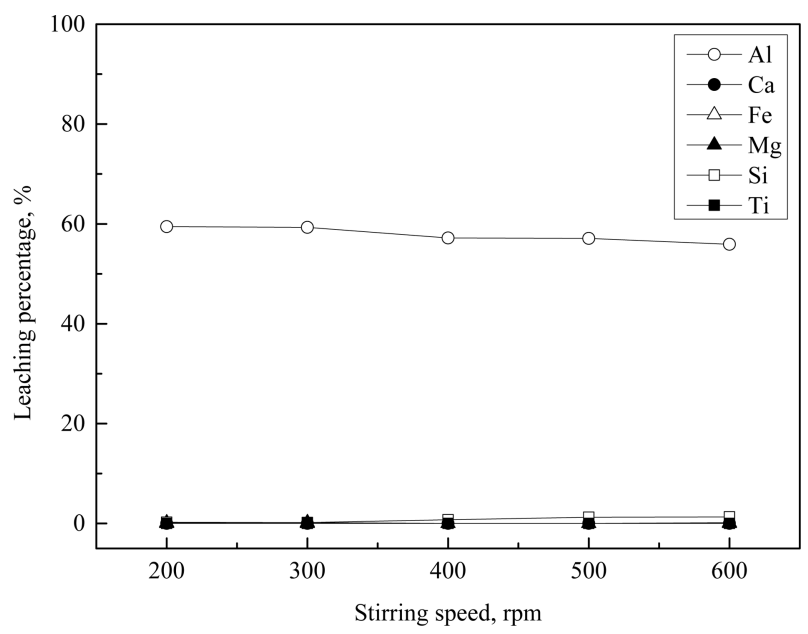

Fig. 6. Effect of stirring speed on the leaching of the oxide from mechanically activated black dross by ultrasound-assisted leaching in $5 \mathrm{M} \mathrm{NaOH}$ solution at $50{ }^{\circ} \mathrm{C}$. (pulp density: $100 \mathrm{~g} / \mathrm{L}$, leaching time: $4 \mathrm{~h}$, ultrasonic power $100 \mathrm{~W})$.

The effect of stirring speed was investigated using $5 \mathrm{M}$ $\mathrm{NaOH}$ at a pulp density of $100 \mathrm{~g} / \mathrm{L}$ and $50^{\circ} \mathrm{C}$, ultrasonic power of $100 \mathrm{~W}$. In these experiments, the mechanically activated dross was leached by varying stirring speeds from 
Table 2. The composition of the leaching solution and the purity of $\mathrm{Al}$ in the solution after $\mathrm{NaOH}$ leaching of the mechanically activated dross at the optimum condition.

\begin{tabular}{cccc}
\hline Composition & $\mathrm{Al}$ & $\mathrm{Si}$ & Purity of $\mathrm{Al}(\%)$ \\
\hline Concentration $(\mathrm{ppm})$ & 20695.8 & 35.95 & 99.8 \\
\hline
\end{tabular}

200 to $600 \mathrm{rpm}$. Within our experimental range, the stirring speed did not show any effect on the leaching of the oxides in the mechanically activated dross (see Fig. 6). The leaching percentage of alumina was about $60 \%$, while that of other oxides was nearly zero under any conditions. The purity of $\mathrm{Al}(\mathrm{III})$ in the leaching solution was $99 \%$ at the leaching time of $4 \mathrm{~h}$ and speed at $200 \mathrm{rpm}$. The composition of the leaching solution and purity of $\mathrm{Al}(\mathrm{III})$ in the solution after $\mathrm{NaOH}$ leaching is shown in Table 2.

\subsection{Combination of ultrasound and different chemical additives in $\mathrm{NaOH}$ leaching}

3.4.1. $\mathrm{CaCl}_{2}$ roasting combined with $\mathrm{NaOH}$ ultrasound-assisted leaching

In black dross, alumina might exist as either $\alpha-\mathrm{Al}_{2} \mathrm{O}_{3}$ or $\gamma$ $\mathrm{Al}_{2} \mathrm{O}_{3}$. Some literatures have reported that $\alpha-\mathrm{Al}_{2} \mathrm{O}_{3}$ is difficult to dissolve in alkaline or acid solution [24]. The combined effect of high temperature and salt addition was investigated [25]. Unlike alumina, $\mathrm{CaO}$ does not dissolve in strong alkaline solution. Therefore, the addition of $\mathrm{CaCl}_{2}$ as a calcium ion source was tried. These samples were used for ultrasound-assisted leaching in a $5 \mathrm{M} \mathrm{NaOH}$ at $50{ }^{\circ} \mathrm{C}$ for 2 hours, ultrasonic power of $100 \mathrm{~W}$. However, the results showed that the presence of $\mathrm{Ca}$ (II) can lead to the precipitation of dissolved alumina and silica in the $\mathrm{NaOH}$ solution [26]. As the weight ratio of $\mathrm{CaCl}_{2}$ to black dross increased, the leaching percentage of silica decreased, and no silica was dissolved when the weight ratio was higher than 1.5 (see Fig. 7). The leaching percentage of alumina decreased rapidly when the weight ratio of $\mathrm{CaCl}_{2}$ to black dross was increased. No oxides of $\mathrm{Ca}, \mathrm{Fe}, \mathrm{Mg}$, and $\mathrm{Ti}$ were dissolved in these experiments.

The predominant species of dissolved alumina and silica in $5 \mathrm{M} \mathrm{NaOH}$ solution were $\mathrm{Al}(\mathrm{OH})_{4}^{-}$and $\mathrm{H}_{3} \mathrm{SiO}_{4}^{2-}$, respectively [27]. In the presence of calcium ions, the silicate and aluminate can form precipitates with the calcium ions, and the reactions are represented as Eqs. (5) and (6) [27]

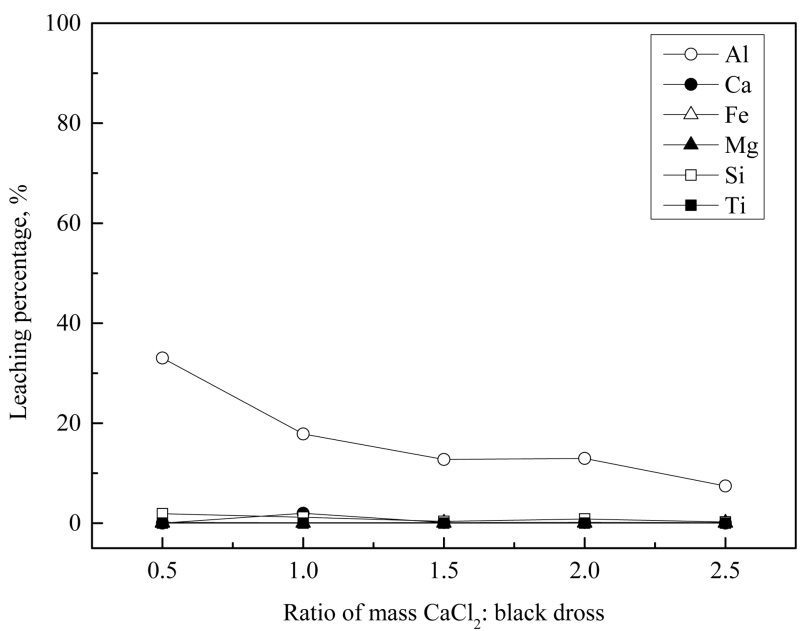

Fig. 7. Effect of ratio of mass $\mathrm{CaCl}_{2}$ : black dross on the leaching of the oxide from mechanically activated black dross by ultrasoundassisted leaching in $5 \mathrm{M} \mathrm{NaOH}$ solution at $50{ }^{\circ} \mathrm{C}$. (pulp density: 100 $\mathrm{g} / \mathrm{L}$, leaching time: $2 \mathrm{~h}$, ultrasonic power $100 \mathrm{~W}$ ).

$$
\begin{aligned}
& \mathrm{Ca}^{2+}+\mathrm{H}_{3} \mathrm{SiO}_{4}^{-}=\mathrm{CaO} \cdot \mathrm{mSiO}_{2}+\mathrm{H}_{3} \mathrm{O}^{+} \\
& \mathrm{Ca}^{2+}+2 \mathrm{Al}(\mathrm{OH})_{4}^{-}+4 \mathrm{OH}^{-}=3 \mathrm{CaO} \cdot \mathrm{Al}_{2} \mathrm{O}_{3} \cdot 6 \mathrm{H}_{2} \mathrm{O}
\end{aligned}
$$

Moreover, the reaction product of Eq. (6) can further react with silicate ions through Eq. (7) on the surface of the precipitates, to form a hydrated Ca-Al-Si-O compound [28].

$$
\begin{aligned}
& 3 \mathrm{CaO} \cdot \mathrm{Al}_{2} \mathrm{O}_{3} \cdot 6 \mathrm{H}_{2} \mathrm{O}+\mathrm{xSiO}_{3}^{2-} \\
& =3 \mathrm{CaO} \cdot \mathrm{Al}_{2} \mathrm{O}_{3} \cdot \mathrm{xSiO}_{2} \cdot(6-2 \mathrm{x}) \mathrm{H}_{2} \mathrm{O}+2 \mathrm{x}(\mathrm{OH})^{-}+\mathrm{mH}_{2} \mathrm{O}(7)
\end{aligned}
$$

where $\mathrm{x}$ depends on the experimental conditions.

Although a pure $\mathrm{Al}(\mathrm{III})$ solution can be obtained by leaching the mixture of black dross and $\mathrm{CaCl}_{2}$ in $\mathrm{NaOH}$ solution in the presence of ultrasonic waves, the low leaching percentage of alumina under these conditions indicates the unsuitability of adding $\mathrm{CaCl}_{2}$ to the black dross.

\subsubsection{The presence of reducing agent in $\mathrm{NaOH}$ ultrasound-assisted leaching}

Some literatures have reported that the addition of organic reducing agents such as oxalic acid, tartaric acid and citric acid can improve the leaching percentage of several metals $[29,30]$. The effect of reducing agent on the leaching of alumina and silica from the mechanically activated black dross was investigated by using $5 \mathrm{M} \mathrm{NaOH}$ at a pulp density of $100 \mathrm{~g} / \mathrm{L}$ and $50{ }^{\circ} \mathrm{C}$, ultrasonic power of $100 \mathrm{~W}$. The effects 
Table 3. The leaching percentage of $\mathrm{Al}$ after $\mathrm{NaOH}$ Ultrasoundassisted leaching without and with presence of organic from black dross at $50{ }^{\circ} \mathrm{C}, 2 \mathrm{~h}$.

\begin{tabular}{ccccc}
\hline Element & \multicolumn{4}{c}{ Leaching percentage (\%) } \\
\hline & $\begin{array}{c}\text { Without } \\
\text { organic }\end{array}$ & $\begin{array}{c}\text { With Oxalic } \\
\text { acid }\end{array}$ & $\begin{array}{c}\text { With } \\
\text { Tartaric acid }\end{array}$ & $\begin{array}{c}\text { With Citric } \\
\text { acid }\end{array}$ \\
\hline $\mathrm{Al}$ & 44 & 49.3 & 45.5 & 43.6 \\
\hline $\mathrm{Si}$ & 0.23 & 7.56 & 6.72 & 5.28 \\
\hline
\end{tabular}<smiles>O=C(O)CC(O)(CC(=O)O)C(=O)O</smiles>

Citric acid<smiles>O=C(O)C(O)C(O)C(=O)O</smiles>

Tartaric acid<smiles>O=C(O)C(=O)O</smiles>

Scheme. 1. A possible configuration of each organic acid.
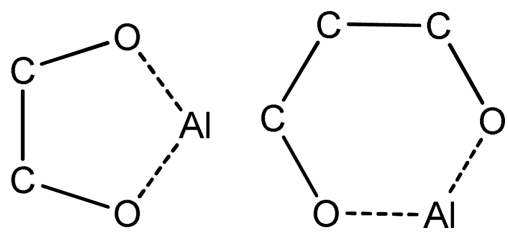

Scheme. 2. The formation of stable 5- or 6-bond ring structures with $\mathrm{Al}$

of some organic reducing agents are shown in Table 3. Clearly, organic reducing agents increased the solubility of aluminum in an alkaline solution [31].

The addition of a carboxylic acid to the solution causes competition between ligands for coordination sites on the metal ions [32]. This creates competition between $\mathrm{OH}$ and other ligand groups with metal ions. From the structural configurations of these acids (scheme 1), deprotonation in the hydroxyl groups of organic acids can occur. Alumina atoms can form coordination bonds between these deprotonated groups and the free electron pair of the oxygen atom on the $\mathrm{CO}$ double bond. The relative positions of hydroxide and carboxylate in the 5- or 6-bong ring structure with $\mathrm{Al}(\mathrm{III})$ might enhance the dissolution of alumina in an $\mathrm{NaOH}$ solution containing organic acid (see scheme 2) [33,34]. Thus, the enhancement of the complexation of the dissolved metal ion with the organic ligands and hydroxide ion may be responsible for the increased leaching efficiency of alumina and silica in $\mathrm{NaOH}$ solution.

Although the leaching percentage of alumina increased, some of the silica was also leached. Therefore, the addition of organic reducing agents is not recommended for the dissolution of alumina in terms of the purity of $\mathrm{Al}(\mathrm{III})$ in the leaching solution.

\section{CONCLUSIONS}

To recover the alumina present in black dross in a previous work, leaching of the mechanically activated black dross in $\mathrm{NaOH}$ solution was performed. Although the purity of $\mathrm{Al}(\mathrm{III})$ in the leaching solution was $98 \%$ under the optimum conditions, the leaching percentage of alumina was only $35 \%$. Under most leaching conditions, only alumina and a small amount of silica were dissolved, while the oxides of $\mathrm{Ca}, \mathrm{Fe}, \mathrm{Mg}$, and Ti were not dissolved. Among the leaching variables, leaching time had a remarkable effect on the dissolution of alumina as the reaction time increased to $4 \mathrm{~h}$. The use of ultrasound waves increased the leaching percentage of alumina to $60 \%$ and the purity of aluminum to higher than 99\%. Therefore, ultrasound waves were confirmed to have a favorable effect on the separation of alumina from silica during leaching in $\mathrm{NaOH}$ solution.

The effect of the combination of ultrasound and the addition of $\mathrm{CaCl}_{2}$ and organic acids to the $\mathrm{NaOH}$ solution on the separation of alumina from silica by was also investigated. The addition of organic reducing agents to the $\mathrm{NaOH}$ solution resulted in an increase in the leaching percentage of alumina and silica, and thus was not favorable to obtaining a pure aluminum solution from the black dross. Although a pure $\mathrm{Al}(\mathrm{III})$ solution was obtained from the black dross by roasting the black dross with $\mathrm{CaCl}_{2}$ followed by $\mathrm{NaOH}$ leaching in the presence of ultrasonic waves, it did not improve the leaching percentage of alumina.

\section{ACKNOWLEDGEMENTS}

This work was supported by the Global Excellent Technology Innovation of the Korea Institute of Energy Technology Evaluation and Planning (KETEP), granted 
financial resource from the Ministry of Trade, Industry \& Energy, Republic of Korea (No.20165010100880). We express sincere thanks to the Korea Basic Science Institute (KBSI), Gwangju branch for providing ICP-OES data.

\section{REFERENCES}

1. O. Manfredi, W. Wuth, and I. Bohlinger, JOM 49, 48 (1997).

2. B. Dash, B. R. Das, B. C. Tripathy, I. N. Bhattacharya, and S. C. Das, Hydrometallurgy 92, 48 (2008).

3. N. S. A. Zauzi, M. Z. H. Zakaria, R. Baini, M. R. Rahman, N. Mohamed Sutan, and S. Hamdan, Adv. Mater. Sci. Eng. 2016, 1 (2016).

4. H. I. So, J. E. Lee, Y. C. Cho, J. W. Ahn and H. J. Ryu, Korean J. Met. Mater. 56, 511 (2018).

5. P. E. Tsakiridis, P. Oustadakis, and S. Agatzini-Leonardou, J. Environ. Chem. Eng. 1-2, 23 (2013).

6. W. J. Bruckard and J. T. Woodcock, Miner. Eng. 20, 1376 (2007).

7. Y. T. Kim and K. W. Yi, Met. Mater. Int. 25, 238 (2018).

8. H. Güngör and A. Elik, Microchem. J. 86, 65 (2007).

9. Y. L. Pang, A. Z. Abdullah, and S. Bhatia, Desalination 277, 1 (2011)

10. L. Zhang, W. Guo, J. Peng, J. Li, G. Lin, and X. Yu, Ultrason. Sonochem. 31, 143 (2016).

11. S. Lu, X. Yang, L. Hao, S. Wu, X. Fang, and J. Wang, Met. Mater. Int. 6, 1 (2018).

12. K. Lim and B. Son, Int. J. Emerg. Technol. Adv. Eng. 5, 25 (2015).

13. A. V. Bese, Ultrason. Sonochem.14, 790 (2007).

14. W. D. Xing, B. D. Ahn, and M. S. Lee, J. Korean Inst. Resour. Recycl. 26, 53 (2017).

15. T. Nguyen, M. Lee, and T. Nguyen, Processes 6, 29 (2018).

16. L. D. Castro and F. P. Capote, Tech. Instrum. Anal. Chem.
26, 99 (2007).

17. R. S. Davidson, A. Safdar, J. D. Spencer, and B. Robinson, Ultrasonics 25, 35 (1987).

18. S. Pilli, P. Bhunia, S. Yan, R. J. LeBlanc, R. D. Tyagi, and R. Y. Surampalli, Ultrason. Sonochem. 18, 1 (2011).

19. H. Grénman, E. Murzina, M. Ronnholm, K. Er“anen, J. P. Mikkola, M. Lahtinen, T. Salmi, and D. Y. Murzin, Chem. Eng. Process. 46, 862 (2007).

20. P. Zhang, Y. Ma, and F. Xie, J. Mater. Cycles Waste 15, 530 (2013).

21. S. Q. Su, J. Yang, H. W. Ma, F. Jiang, Y. Q. Liu, and G. Li, Integr. Ferroelectr. 128, 155 (2011).

22. M. Hossein-Zadeh, M. Razavi, O. Mirzaee, and R. Ghaderi, J. King Saud Univ. Eng. Sci. 25, 75 (2013).

23. P. D. Tomke and V. K. Rathod, Ultrason. Sonoche. 27, 241 (2015).

24. B. R. Editor, J. Am. Chem. Soc. 129, 5296 (2007).

25. Y. Sun, Z. Liang, and F. Sun, J. Environ. Anal. Toxicol. 7, 2 (2017).

26. S. J. Kim, J. I. Lee, K. S. Han, S.Y. Byun, T. Tran, and M. J. Kim, Korean J. Met. Mater. 56, 49 (2018).

27. J. H. Kang, W. Sun, Y. H. Hu, Z. Y. Gao, R. G. Liu, Q. P. Zhang, H. Liu, and X. S. Meng, Water Res. 125, 318 (2017).

28. A. Noworyta, Hydrometallurgy 7, 107 (1981).

29. V. H. Nguyen, G. R. Craddock, and F. A. Dams, Soil Sci. Soc. Am. J. 50, 28 (1986).

30. R. J. Bartlett and D. C. Riego, Plant Soil. 37, 419 (1972).

31. S. Goldberg, J. A. Davis, and J. D. Hem, The enviroment chemistry of aluminum, 2nd ed., pp. 272-318, CRC Press, New york (1995).

32. E. I. Christopher C. Boyd, Master thesis, pp.11-12, Central Florida University, Orlando (2011).

33. R. J. Motekaitis and A. E. Martell, Inorg. Chem. 23, 18 (1984).

34. M. Schnitzer, Soil Sci. Soc. Am. 33, 75 (1969). 